\title{
Investigation of possible pharmacokinetic interaction of metformin with sugar replacement sweeteners in rats
}

\author{
Riad Awad ${ }^{1}$, Eyad Mallah ${ }^{1}$, Israa Al-Ani ${ }^{2}$, Wael Abu Dayyih ${ }^{1}{ }^{*}$, Zainab Zakarya $^{1}$, Tawfiq Arafat ${ }^{1}$ \\ ${ }^{1}$ Faculty of Pharmacy and Medical Silences, University of Petra, Queen Alia International Road, P.O. Box: 961343, Amman - Jordan. \\ ${ }^{2}$ Faculty of Pharmacy and Medical Silences, Al-Ahliyya Amman University, Amman, Jordan.
}

\begin{tabular}{|c|c|}
\hline ARTICLE INFO & ABSTRACT \\
\hline $\begin{array}{l}\text { Article history: } \\
\text { Received on: } 09 / 07 / 2016 \\
\text { Revised on: } 08 / 08 / 2016 \\
\text { Accepted on: } 22 / 08 / 2016 \\
\text { Available online: } 29 / 10 / 2016\end{array}$ & $\begin{array}{l}\text { Metformin is widely used for type II diabetes. Sugar replacement sweeteners such as Aspartame and Stevia, are } \\
\text { usually consumed concomitantly with other antidiabetics by patients The aim of this work is to investigate } \\
\text { possible effects of two types of sweeteners; stevia and aspartame on the pharmacokinetic parameters of } \\
\text { metformin in rats. A simple, validated bio-analytical HPLC method was developed to measure metformin in rat } \\
\text { plasma. Three groups of rats, each of eight were subjected to this study. The first group was given metformin } \\
\text { a }\end{array}$ \\
\hline $\begin{array}{l}\text { Key words: } \\
\text { Metformin, stevia, } \\
\text { aspartame, HPLC, } \\
\text { Pharmacokinetic. }\end{array}$ & $\begin{array}{l}\text { group was given } 20 \mathrm{mg} / \mathrm{kg} \text { metformin with } 10 \mathrm{mg} / \mathrm{kg} \text { aspartame on fasting state. Blood samples were taken on } \\
\text { scheduled time interval up to } 6 \text { hours and analyzed for metformin concentration. Pharmacokinetic parameters } \\
\text { were calculated by Non-Compartmental Model and data were interpreted. The results showed that } \\
\text { administration of these two sweeteners did not have high effect on pharmacokinetics of metformin. }\end{array}$ \\
\hline
\end{tabular}

\section{INTRODUCTION}

Metformin is a biguanide oral hypoglycemic agent which is commonly used in type II diabetes mellitus. It was introduced after the restriction of phenformin due to less side effect especially lactic acidosis (Berbman, 1978). It was approved by FDA 1n 1994.Metformin exerts its activity by multiphase effects on GIT in lowering glucose absorption and liver by inhibition of glucose synthesis as well as increasing glucose uptake by cells without increasing the level of insulin (Hermann and Malender, 1992; Cusi and Defr, 1998). Several studies have described the pharmacokinetic behavior of metformin after oral and parenteral administration. Metformin has an oral bioavailability of $40-60 \%$ of the orally administered dose under fasting conditions and the rest is recovered in feces (Al Hawari et al., 2007). Lack of dose proportionality, and the drug being a polar ionizable compound in the GIT, suggest the involvement of saturable mechanism of a transport system (Müller et al., 2005; Lipton et al., 1992). The absorption process

* Corresponding Author

Email : wabudayyih@ @op.edu.jo is slow and the peak plasma concentration reaches between 2-5 hours and food decreases both rate and extent of absorption (Dunn and Peters, 1995; Scheen, 1996). It has negligible plasma protein binding and it is excreted in urine as unchanged drug (Garry et al., 2015). Its excretion rate was found to correlate partially with creatinine clearance suggesting filtration through glomeruli. However, its clearance is higher than that of creatinine which suggests the involvement of active tubular secretion (Lipska et al., 2011; Pentikäine, 2011). Metformin has an average volume of distribution for adults of $654 \pm 358 \mathrm{~L}$.

This high volume of distribution of this polar compound is due to partitioning to RBCs as a function of time (Raj et al., 2011). Artificial sweeteners are widely used nowadays especially by people with type II diabetes and people on special diet to avoid ingestion of extra calories. Many types of sweeteners are found in the market; some of natural source and others are synthetic compounds. Some sweeteners have been withdrawn from the market; like cyclamate, for its carcinogenicity (O'Brien-Nabors, 2011). Stevia is a naturally occurring material extracted from the plant Stevia rebaudiana which has been commercialized as a sweetener. Stevia contains two major glycosides Stevioside and Rebaudioside. 
These two compounds are hundreds of times sweeter than sugar (Raji and Mohamad, 2012). Stevia has been studied for its sugar lowering effect in type II diabetes. Some studies have shown the sugar lowering effect of stevia compared to other sweeteners such as regular sugar and aspartame (Gregersen et al., 2004; Anton et al., 2010; Dunn and Peters, 2000).

Aspartame is a non-saccharide sweetener used as a sugar substituent in food and beverages. It is synthesized from two amino acids; aspartic acid and phenylalanine (Magnuson et al., 2007). It was introduced in 1965 (Mazur, 1984), and since that time there were many regulations regarding its safety for human (Butchko et al., 2002). Based on many studies , the European Food Safety Authority stated in 2013 that aspartame is safe in human except for those who have phenylketonuria due to their inability to metabolize phenylalanine; the aspartame breakdown product (Stegink et al., 1977).

Previous studies have described pharmacokinetic interaction between drugs and sugar replacement sweeteners like pioglitazone $\mathrm{HCl}$ with sucralose (Tamimiet al., 2014). This made studying these possible interactions of special importance. The aim of this study is to investigate possible pharmacokinetic interaction between metformin and both stevia and aspartame in rats.

\section{EXPERIMENTAL}

\section{Materials}

Metformin and cefadroxil (the internal standard) were of analytical purity grade and purchased from United Pharmaceuticals. 1-Hexanesulfonic acid sodium salt was purchased from Chromanorm, potassium dihydrogen phosphate buffer was obtained from Scharlau, and trichloroacetic acid
(MERCK). Methanol, water and acetonitrile were of HPLC grade (Chromanorm), Stevia (Qingdao Qingmei Biotech. Co. Ltd, China, 90\% steviosideand $98 \%$ rebaudioside purity), Aspartame (NIUTANG, China, 98\%-102\% purity).

\section{HPLC method of analysis of metformin in rat plasma Instrument and Chromatographic conditions}

An HPLC (Finnigan Surveyor) was used in this study and it composes of the following: ChromQuest software 4.2.34 Solvent delivery systems pump (LC Pump Plus), autosampler Plus, UV-VIS Plus Detector, Hypersil Thermo Electron Corporation, BDS C-18 Column (150 mm x $4.6 \mathrm{~mm}, 5 \mu \mathrm{m})$ and computer System, Windows XP, SP3.

Table 1: Chromatographic conditions of HPLC analysis of Metformin.

\begin{tabular}{ll}
\hline \multicolumn{1}{c}{ Parameter } & \multicolumn{1}{c}{ Value } \\
\hline Pump Flow Rate & $0.9 \mathrm{ml} / \mathrm{min}$ \\
Autosampler Injection Volume & $50 \mu 1$ \\
AutosamplerTemp. & $10^{\circ} \mathrm{C}$ \\
$\begin{array}{l}\text { Column Oven Temp } \\
\text { Retension time (min.) }\end{array}$ & $25^{\circ} \mathrm{C}$ \\
$\begin{array}{l}\text { Cefadroxil (Internal Std) } \\
\text { Retension time (min.) }\end{array}$ & 4.6 \\
$\begin{array}{l}\text { Metformin } \\
\text { wavelength }\end{array}$ & 7 \\
\hline
\end{tabular}

Chromatographic conditions are described in Table (I). The mobile phase consisted of $90 \%$ water containing $7.5 \mathrm{mM}$ potassium dihydrogen phosphate buffer and $15 \mathrm{mM}$ 1hexanesulfonic acidsodium salt and $10 \%$ of acetonitrile was circulated through a reversed-phase Thermo Scientific column (BDS HYPERSIL $\mathrm{C} \mathrm{18}$ ) at a flow rate of $0.9 \mathrm{ml} /$ minute. Absorbance was measured at wavelength $234 \mathrm{~nm}$. The chromatogram is shown in Fig. 1.

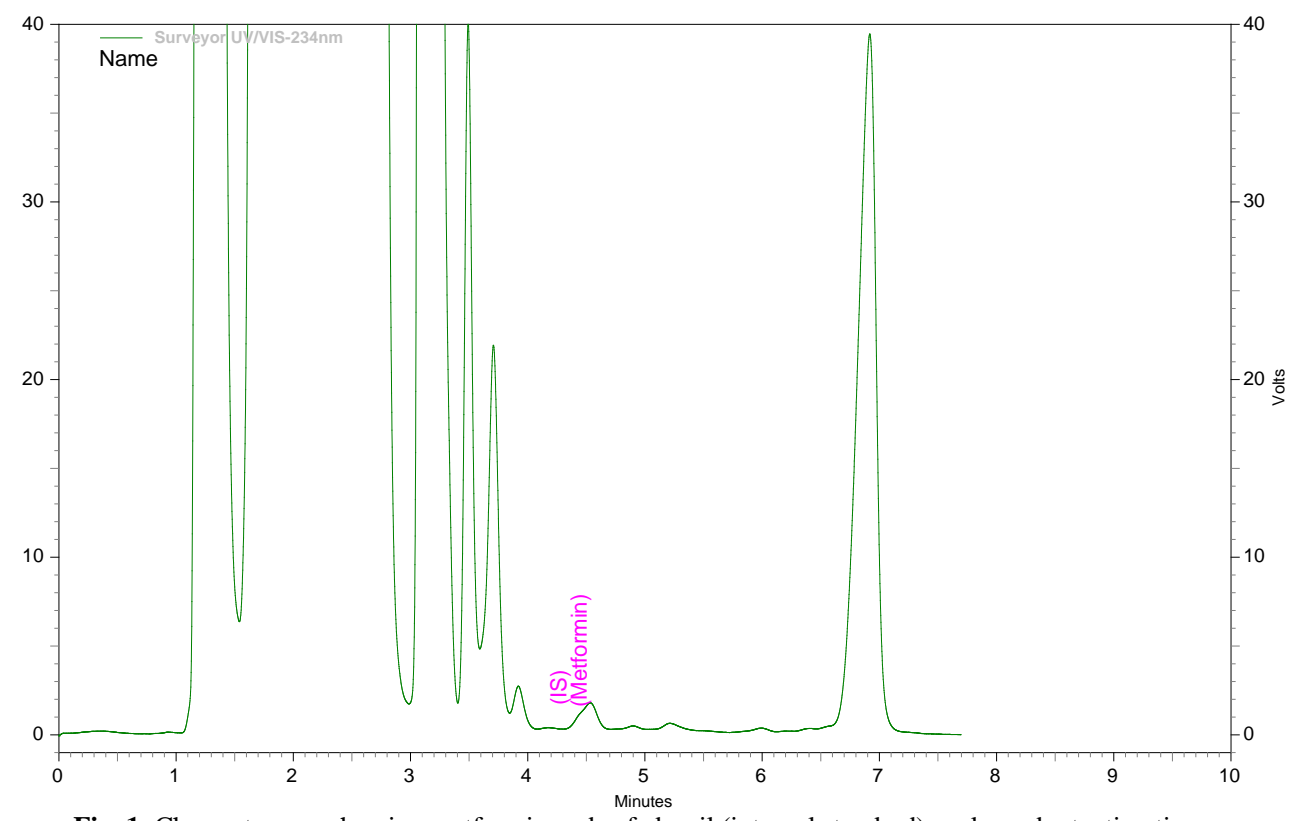

Fig. 1: Chromatogram showing metformin and cefadroxil (internal standard) peaks and retention time. 


\section{Method of extraction}

To perform the sample extraction, the following procedure was followed: $150.0 \mu \mathrm{l}$ aliquots of internal standard $(5 \mu \mathrm{g} / \mathrm{ml}$ cefadroxil) by pipette. After the vortex of each sample vigorously for $1.0 \mathrm{~min}$., and the centrifugation at $14000 \mathrm{rpm}$ for 15 minutes. A clear supernatant was transferred to a flat bottom insert and $50 \mu \mathrm{l}$ was injected directly into HPLC system.

The described procedures were applied for subject samples, standards and quality control samples.

\section{Method validation}

Linearity, precision ,accuracy, limit of quantification and recovery were measured according to EMEA guideline. Regarding linearity, seven calibration points $(25 \mathrm{ng} / \mathrm{ml}, 50 \mathrm{ng} / \mathrm{ml}, 200 \mathrm{ng} / \mathrm{ml}$, $500 \mathrm{ng} / \mathrm{ml}, 1000 \mathrm{ng} / \mathrm{ml}, 2000 \mathrm{ng} / \mathrm{ml}$ and $2500 \mathrm{ng} / \mathrm{ml}$ ) were involved. Peak areas of the calibration standards were plotted against the nominal standard concentration. The linearity of the plotted curve was evaluated by calculation of the correlation coefficient $\left(\mathrm{R}^{2}\right)$ which was equal to0.999.

The intra-day precision and accuracy were evaluated by analyzing six replicas of the quality control (QC) samples (low, mid, high) and lower limit of quantization (LLOQ) samples on a single day. The inter-day precision and accuracy were determined by analyzing three runs of QC samples and LLOQ samples on three different days.

The accuracy (\%) was calculated by dividing the measured mean concentration over the nominal concentration. Precision was presented as CV\%. The acceptable values of accuracy and precision are below $15 \%$ except at the LLOQ, for which accuracy and precision should be below 20\%.the lowest concentration of target metformin had been given at least 5 times the response as compared with the signal of the blank which was considered as limit of quantification (LOQ)The quantitation of metformin in rat plasma was done by reading the analyte response against the calibration curve parameters .The recovery of metformin was estimated as percentage of concentration in rat plasma by comparing the peaks area spiked plasma as standards with those of corresponding plain standards which contains the concentration in mobile phase which represent $100 \%$

\section{Animals}

Twenty four male and female Sprague-Dawley rats weighing (200-250g) weight were housed in a conditioned environment with $12 \mathrm{~h}$ light/dark cycles and room temperature. Food and water were available ad libitum until $12 \mathrm{~h}$ prior to experiment. Before experiment, the food was removed and rats were kept fasting overnight. The experimental protocol had been approved by the ethics committee of the Research Council, Faculty of Pharmacy and Medical Sciences, University of Petra, Amman, Jordan.

\section{Study design}

Metformin $(20 \mathrm{mg} / \mathrm{kg})$ was dissolved in distilled water and freshly prepared at the day of the experiment. Stevia solution was prepared by dissolving the powder in distilled water and the dose was $4 \mathrm{mg} / \mathrm{Kg}$; an acceptable daily intake. Aspartame was prepared by the same method and its dose was $10 \mathrm{mg} / \mathrm{Kg}$ which is an FDA acceptable daily intake.

The rats received a calculated volume of each solution according to their weights by using a stainless steel oral gavage needle. Rats were randomly divided into three groups each of 8 animals

The first group received metformin, then the second group received metformin immediately followed by stevia solution. While the third group received metformin and aspartame by the same method.Blood samples were taken from the tail vein into an EDTA containing micro-tubes at the following time points: $0.5,1.0,1.5,2.0,2.5,3.0,4.5,6.0$ hours and stored at deep freezing $\left(-20^{\circ} \mathrm{C}\right)$ until time of analysis.

\section{Pharmacokinetic analysis}

Metformin was studied in both human and rat as a three compartmental model, but in other studies data fits one compartmental model (Sun et al., 2011, William et al., 2008). Also some studies results have also shown double peak phenomena which does not appear in others (Stephen et al., 2008). Because of these variations, and the short time of analysis, noncompartmental analysis was utilized to calculate kinetic parameters in this study.

The data was treated by Kinetica ${ }^{\circledR}$ version 4 and the following parameters were calculated: $\mathrm{Cp}_{\max }, \mathrm{T}_{\max }, \mathrm{AUC}_{0 \text {-last }}$, $\mathrm{AUC}_{0-\infty}, \mathrm{AUMC}_{0 \text {-last }}, \mathrm{AUMC}_{0-\infty}$, Clearance $(\mathrm{Cl})$, mean residence time (MRT), elimination rate constant $\left(\mathrm{K}_{\mathrm{el}}\right)$ and volume of distribution $\left(\mathrm{V}_{\mathrm{d}}\right)$. These parameters were calculated for metformin alone, metformin with stevia and metformin with aspartame.

\section{Statistical analysis}

All data were plotted as mean concentration versus time. Standard deviation and Standard error were also calculated for each group data in each concentration point using same version of kinetica $^{\circledR}$.

Also, t-test was used to compare some parameters using confidence interval of $5 \%$ by online GraphPad. $\mathrm{p}<0.05$ was considered as a significant variation and $p>0.05$ as non-significant.

\section{RESULTS AND DISCUSSION}

\section{Method of analysis validation}

Using the defined chromatographic method, metformin and cefadroxil were separated within 6 minutes run time as shown in (Fig. 1).

The correlation coefficient $(\mathrm{R})$ for the calibration curve of metformin for each run was more than 0.999. Furthermore, the intra-day and the inter-day accuracy values of metformin were between (100.74-104.65\%) and (100.99-103.75\%), respectively, while the intra- and inter-day precision values were less than $4.62 \%$ and $4.42 \%$, respectively (Table II). 
Table 2: Validation results of the HPLC method used for analyzing metformin in Sprague-Dawley rats' plasma.

\begin{tabular}{ll}
\hline \multicolumn{1}{c}{ Parameter } & \multicolumn{1}{c}{ Value } \\
\hline $\begin{array}{l}\text { Linearity }\left(\mathrm{R}^{2}\right) \\
\text { linearity equation }\end{array}$ & 0.999 \\
$\begin{array}{l}\text { Accuracy (\%) } \\
\text { intra-day accuracy (range) }\end{array}$ & $\mathrm{Y}=0.000725 \mathrm{X}-0.002026$ \\
inter-day accuracy (range) & $(100.74-104.65 \%)$ \\
$\begin{array}{l}\text { Precision (CV\%) } \\
\text { intra-day precision (less than) }\end{array}$ & $(100.99-103.75 \%)$ \\
inter-day precision (less than) & $4.62 \%$ \\
Stability (\%) & $4.42 \%$ \\
Short term & \\
Auto-sampler & Stable for $8 \mathrm{hr}$ \\
Freeze thaw & Stable for $24 \mathrm{~h}$ \\
Recovery $(\%)$ & Stable for 3 cycles \\
\hline
\end{tabular}

\section{Non compartmental pharmacokinetic analysis}

Plots of plasma level of metformin alone, metformin with stevia and metformin with aspartame are shown in Fig. 2.. Concentrations in plasma are presented in $\mathrm{ng} / \mathrm{ml}$ and were calculated as average \pm SD.

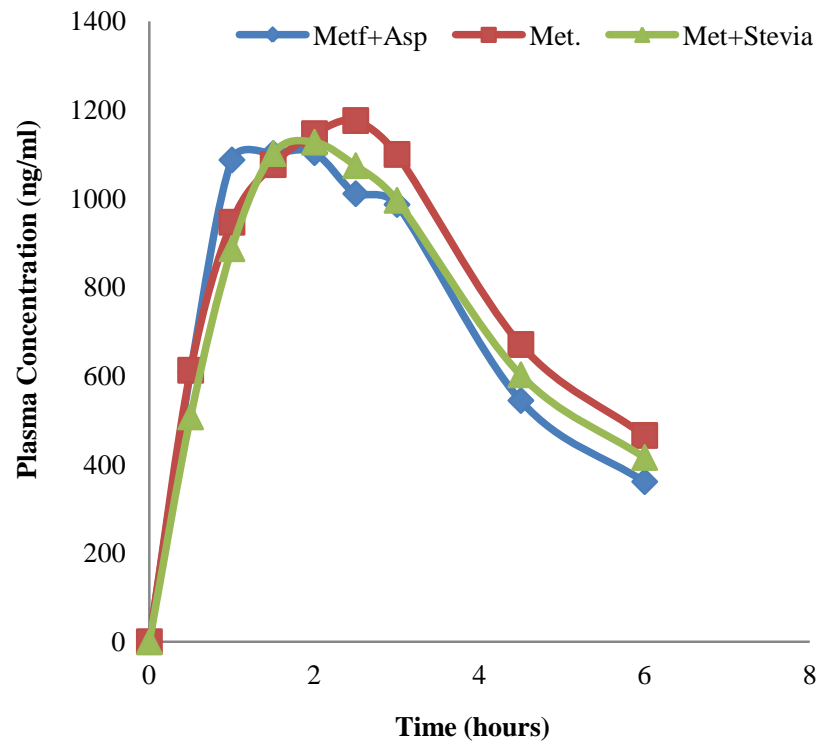

Fig. 2: Rat plasma levels-timeplot of metformin, metformin with aspartame and metformin with stevia.

Pharmacokinetic parameters of metformin taken alone and with either stevia or aspartame are presented in table (III). Cpmax was changed with concomitant administration of the sweeteners with metformin, but this slight decrease was statically non-significant upon comparison by t-test.

Tmax for the three groups of animal was between 2-2.5 hours. AUC0-6 was decreased when metformin was taken with the

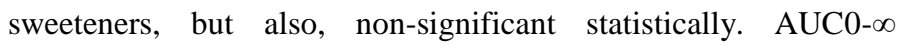
decreased with the administration with aspartame. The terminal elimination rate constant was increased in case of aspartame. Other parameters were calculated based on formulas that depend mainly on the calculation of AUC.

Metformin is a highly soluble polar compound. Its mechanism of absorption was revealed by many studies mainly as saturable transporter-mediated mechanism with some of it that might cross the membrane from small intestine by passive diffusion. The permeation step is usually the rate limiting step of absorption, which made time to reach maximum concentration in plasma long. However, elimination through renal excretion is usually fast which made absorption factors mostly responsible for the shape of the plasma level-time profile, or what is known as (flip-flop) phenomena (Englund et al., 2006).

Table 3: Pharmacokinetic parameters calculated by non-compartmental analysis of metformin, metformin administered with Stevia and metformin with Aspartame.

\begin{tabular}{|c|c|c|c|}
\hline $\begin{array}{c}\text { Pharmacokinetic } \\
\text { parameter }\end{array}$ & Metformin & $\begin{array}{c}\text { Metformin } \\
\text { +Stevia }\end{array}$ & $\begin{array}{c}\text { Metformin }+ \\
\text { Aspartam }\end{array}$ \\
\hline Cpmax (ng/ml) & 1175.7 & 1126.989 & 1103.126 \\
\hline Tmax (hr) & 2.5 & 2 & 2 \\
\hline AUC0-6 (ng.hr/ml) & 4922.896 & 4041.170 & 4548.512 \\
\hline 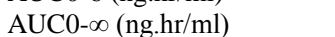 & 6416.044 & 5459.508 & 5603.093 \\
\hline AUMC0-6(ng.hr²/ml) & 13477.512 & 12787.470 & 12143.750 \\
\hline 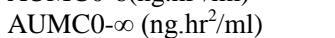 & 27567.484 & 26265.220 & 21787.600 \\
\hline MRT0-6 (hr) & 2.737 & 3.18 & 2.681 \\
\hline MRT0- $\infty(\mathrm{hr})$ & 4.29 & 4.80 & 3.888 \\
\hline Terminal Kel( $\left(\mathrm{hr}^{-1}\right)$ & 0.291 & 0.291 & 0.336 \\
\hline Total Clearance $(\mathrm{L} / \mathrm{hr} / \mathrm{kg})$ & 2.9 & 3.65 & 3.569 \\
\hline $\begin{array}{l}\mathrm{Vd} \text { (volume of distribution) } \\
\mathrm{L} / \mathrm{kg}\end{array}$ & 14.8167 & 17.50 & 13.87 \\
\hline Half-life & 2.38 & 2.38 & 2.06 \\
\hline
\end{tabular}

On the other hand, the glycosides of stevia were shown to be unabsorbed significantly from small intestine and to be cleaved in colon by bacteria to the aglycon part and the sugar moiety (Raji and Mohamad, 2012). This makes the interaction of Stevia with metformin on the absorption site unlikely. The Cpmax of metformin with Stevia (1126.989 $\pm 120.9 \mathrm{ng} / \mathrm{ml}$ ) and the $\mathrm{AUC}_{0 \text { - }}$ last $(4041.170 \mathrm{ng} . \mathrm{hr} / \mathrm{ml})$ were insignificantly changed from those of metformin alone $(1175.7 \pm 106.9 \mathrm{ng} / \mathrm{ml})$ and $(4041.170$ ng.hr/ml). These two parameters evaluate the extent of bioavailability and so, this reveals low possibility of interaction on absorption level.

Tmax is the parameter that evaluates rate of bioavailability. Results showed a slight decrease in the Tmax which might be due to the physiological parameters of GIT such as the gastric emptying rate.

TheAUC $_{0-\infty}$ was decreased from 6416.044ng.hr/ml for metformin alone to $5459.508 \mathrm{ng} . \mathrm{hr} / \mathrm{ml}$ for metformin with stevia. In spite of that, the difference is statistically significant, but the short time of sampling $(6 \mathrm{hr})$ and the large estimated $\mathrm{AUC}_{\text {last- }}$, made this area subjected to high percentage of error and so, the $\mathrm{AUC}_{0-6}$ is more accurate specially for absorption phase which is the most important for metformin.

Regarding aspartame; being a dipeptide, it is subjected to cleavage to aspartic acid and phenyl alanine by the action of GI peptidases. Both amino acids are polar, ionized and known to be absorbed from small intestine through transporters-mediated mechanism. However, the decrease in Cpmaxfrom $1175.7 \mathrm{ng} / \mathrm{ml}$ for metformin to $1103.126 \mathrm{ng} / \mathrm{ml}$ with aspartame was found statistically non-significant. This also suggests independent absorption of the drug and the aspartame or its cleavage products. $\mathrm{AUC}_{0-6}$ of metformin alone (4922.89675 ng.hr/L) was also non- 
significantly changed with the administration of aspartame (4548.512 ng.hr/L) suggesting same extent of bioavailability. The same is true for Tmax with half an hour decrease that is not a highly effective time on the absorption of metformin.

Renal excretion of metformin is the major route of elimination. Aspartic acid and phenyl alanine are also excreted actively from kidney and reabsorbed to plasma. The elevation of elimination rate constant of metformin with aspartame and the slight shortening of the half- life might be attributed to the inhibition of some of the reabsorption mechanism of metformin by the amino acid, resulting in higher amount of drug excreted through kidney. The mechanism of metformin reabsorption, although not involving a high percent of the drug, was proposed by several studies (Tzvetkov et al., 2009).

Elimination of metformin was not affected by stevia since stevia is mainly unabsorbed from GIT.

Mean residence time, which represents the time that drug spends in the body regardless of its compartmental distribution, was not highly changed from the time zero up to 6 hours sampling time, with a slight decrease for metformin with aspartame. This suggests almost similar behavior of the drug in all cases.

Total clearance showed a slight increase for metformin with aspartame due to the increase of renal excretion, while steady state volume of distribution showed variability, which is very common with metformin because of partitioning to RBCs and the high range of Vssas shown in many studies.

In summary, stevia and aspartame do not have that prominent effect on the pharmacokinetic parameters of metformin

\section{CONCLUSION}

A validated bioanalytical HPLC method with high resolution and sensitivity was developed for the determination of metformin in rat plasma. Investigation of pharmacokinetic parameters of metformin when given orally to Sprague-Dawley rats with two types of sweeteners; stevia and aspartame, showed that the pharmacokinetic parameters of metformin was not highly affected by concomitant administration of these two sweeteners.

\section{ACKNOWLEDGMENT}

The research team would like to show their gratitude to the Faculty of Pharmacy and Medical Sciences at University of Petra for sharing their pearls of wisdom with them during the course of this research. We are also immensely grateful to all who contributed to this work for their comments and advice.

\section{Financial support and sponsorship: Nil.}

Conflict of Interests: There are no conflicts of interest.

\section{REFERENCES}

Al Hawari S , AlGaai E, Yusuf A, Abdelgaleel A , Hammami MM. Bioequivalence study of two Metformin formulations. Arzneimittel forschung, 2007; 57: 192-195.
Anton S, Martin C, Han H, Coulon S, Cefalu W, Geiselman P,Williamson D. Effects of stevia, aspartame, and sucrose on food intake, satiety, and postprandial glucose and insulin levels. Appetite, 2010; 55:3743.

Berbman U, BowmanG, Wiholm BE. Epidmiology of adverse drug reaction of phenformin and metformin. Br Med J,1978;2:464-466.

Butchko H, Stargel WW, Comer CP, Mayhew DA, Benninger C, Blackburn GL, De Sonneville LM, Geha RS, Hertelendy Z. Aspartame: Review of Safety. RegulToxicolPharmacol, 2002; 35:1-93.

Cusi K, Defr RA. Metformin: a review of its metabolic effect. Diabetes Rev, 1998; 6: 89-131.

Dunn CJ, Peters DH. Metformin: A review of its pharmacological properties and therapeutic use in non-insulin-dependent diabetes mellitus. Drugs, 1995;49: 721-49.

Englund G, Rorsman F, Ronnblom A, Karlbom U, Lazorova L , Grasjo J, Kindmark A, Artursson R. Regional levels of drug transporters along the human intestinal tract: co-expression of $\mathrm{ABC}$ and SLC transporters and comparison with Caco-2 cells. Eur J Pharm Sci, 2006;29: 269-277.

Garry G, JeroenG, Arora M, Day RO, Doogue MP, Duong JK, Furlong TJ, Greenfield JR, Greenup LC, Kirkpatrick CM, Ray JE, Timmins $P$ Williams KM. Clinical Pharmacokinetics of Metformin. ClinPharmacokinet, 2015; 50:81-98.

Gregersen S, Jeppesen PB, Holst JJ, Hermansen K. Antihyperglycemic effects of stevioside in type 2 diabetic subjects. MetabClinExp,2004;53:73-76.

Hermann L,Malender A.Biguanides: basic aspects and clinical uses In: Alberti K,DeFronzoRA, Keen H, Zimmet P. editor.International Textbook of Diabetes Mellitus,eds $1^{\text {st }}$. ed1992.John Wily \& Sons Inc. New York.

Jeppesen PB, Gregersen S, Poulsen $\quad \mathrm{CP}$, Hermansen K.Stevioside acts directly on pancreatic beta cells to secrete insulin: actions independent of cyclic adenosine monophosphate and adenosine triphosphate-sensitive K+-channel activity. Metabolism,2000; 49:208-14.

Lipton WE,Li YN, Younoszai MK, Stegink LD.Intestinal absorption of aspartame decomposition products in adult rats.Metabol, 1991;40:1337-45.

Lipska KJ, Bailey CJ, Inzucchi SE. Use of Metformin in the Setting of Mild-to-Moderate Renal Insufficiency.Diabetes Care, 2011;34:1431-1437.

Lyn O'Brien-Nabors .2011. Alternative Sweeteners. CRC Press.

Mazur RH.Discovery of aspartame. In: SteginkLD and Filer Jr. LJ. Editors. Aspartame: Physiology and Biochemistry. 1984.Marcel Dekker, New York.

Magnuson BA, Burdock GA, Doull J, Kroes RM, Marsh GM, Pariza MW, Spencer PS, Waddell WJ, Walker R, Williams GM.. Aspartame: a safety evaluation based on current use levels, regulations, and toxicological and epidemiological studies. Crit Rev Toxicol, 2007; 37:629-727.

Müller J, Lips KS,Metzner L, Neubert RH, Koepsel H, Brandsch M. Drug specificity and intestinal membrane localization of human organic cation transporters (OCT). Biochem Pharmacol, 2005; 70:1851-1860.

Raj S, Gabr RQ, Lee-AnnAM,Dion SK. Effect of Gastric Bypass Surgery on the Absorption and Bioavailability of Metformin. Diabetes Care, 2011;34: 1295-1300.

Raji A, Mohamad O. Studies on effects of pruning on vegetative traits in Stevia rebaudiana Bertoni (Compositae) . Int J Biol, 2012;4: 146153.

Scheen AJ.Clinical pharmacokinetics of metformin. Clin Pharmacokinet, 1996;30:359-71.

Pentikäinen PJ.Bioavailability of metformin: Comparison of solution, rapidly dissolving tablet, and three sustained release products. Int J Clin Pharmacol Ther Toxicol, 1986; 24:213-20.

Stegink LD, Filer LJ Jr, . Baker GL. Effect of aspartame and aspartate loading upon plasma and erythrocyte free amino acid levels in normal adult volunteers. J nutr, 1977; 107:1837-1845. 
Sun L, Kwok E, Gopaluni B, and Vahidia O. PharmacokineticPharmacodynamic Modeling of Metformin for the Treatment of Type II Diabetes Mellitus. Open Biomed Eng J, 2011;5: 1-7.

Tamimi L, Abudayyih W, Mallah E, Arafat, T. Pioglitazone HCllevels and its pharmacokinetic Application in Presence of Sucralose in Animals Serum by HPLC Method. Pharma Anal Acta, 2014;12:2-7.

Stephen R, KennethC, Turner SP. Pharmacokinetics and Pharmacodynamics of Glyburide/Metformin Tablets (Glucovance ${ }^{\mathrm{TM}}$ ) versus Equivalent Doses of Glyburide and Metformin in Patients with Type 2 Diabetes. Clinpharmacokinet, 2002;41: 1301-1309.

Tzvetkov MV, Vormfelde SV, Balen D, Meineke I, Schmidt T, Sehrt D, Sabolić I, Koepsell H, Brockmöller J.The effects of genetic polymorphisms in the organic cation transporters OCT1, OCT2, and OCT3 on the renal clearance of metformin.Clin Pharmacol Ther, 2009; 86:299-306.

William R, Proctor DL, Bourdet DL, Thakker DL. Mechanisms Underlying Saturable Intestinal Absorption of Metformin. Drug Metab Dispos, 2008;36: 1650-1658.

\section{How to cite this article:}

Awad R, Mallah E, Al-Ani I, Dayyih WA, Arafat T. Investigation of possible pharmacokinetic interaction of metformin with sugar replacement sweeteners in rats. J App Pharm Sci, 2016; 6 (10): 210-215 